\title{
Inter-organizational collaboration for energy efficiency in the maritime sector: the case of a database project
}

\author{
Josefin Borg (iD - Hannes von Knorring
}

Received: 29 November 2018/Accepted: 21 August 2019/Published online: 27 November 2019

(C) The Author(s) 2019

\begin{abstract}
This article explores the complexities of establishing knowledge-sharing practices between organizations through a case study of the creation of a database for energy efficiency measures relevant to the shipping sector. As researchers and policy-makers tend to point towards knowledge sharing and collaboration as means towards a more energy-efficient society, there is a need to better understand the knowledge sharing practices in such initiatives. The study is based upon extensive fieldwork where the first author was recruited to a collaborative network on energy efficiency in the shipping sector, to aid in the development of the collaboration while carrying out participatory-observational research in an ethnographic tradition. The study highlights the need to maintain realistic expectations for new knowledge-sharing collaborations, and the necessity to allow such arrangements to develop over time.
\end{abstract}

Keywords Inter-organizational collaboration · Energy efficiency $\cdot$ Shipping industry $\cdot$ Database

J. Borg $(\bowtie)$

Department of Mechanics and Maritime Sciences, Chalmers University of Technology, 41296 Gothenburg, Sweden e-mail: anna.josefin.borg@gmail.com

H. von Knorring

Gothenburg Research Institute, University of Gothenburg, Box 100, 40530 Gothenburg, Sweden

\section{Introduction}

In May 2018, countries agreed in the International Maritime Organization (IMO), a UN specialized agency, on an initial strategy to reduce total GHG emissions from the international shipping sector by at least $50 \%$ by 2050. Goals were also introduced for carbon intensity: $\mathrm{CO} 2$ emissions per transport work should be reduced by at least $40 \%$ by 2030 , and a $70 \%$ reduction by 2050 should be pursued. Achieving these goals will require a shift towards low carbon fuels along with improvements in energy efficiency. Much work for the EU, the IMO, and for publication in academic journals, has been dedicated towards understanding the scope of the technical potential for reduction (Bouman et al. 2017; Buhaug et al. 2009; Eide et al. 2009, 2011; Faber et al. 2009, 2011). The most recent review by Bouman et al. (2017) identified a potential ranging from 33 to $77 \%$ by 2050 , achievable through implementing already existing measures. A large portion of these are measures that improve energy efficiency. These findings suggest that much could be achieved by gathering and spreading knowledge, experience, and information related to energy efficiency.

In this paper, we present a study of the creation of a database for sharing information on ship performance and on energy efficiency measures within a network for shipowners in a European country. The study is based upon extensive fieldwork where the first author was recruited to aid in the development of the energy efficiency collaboration while carrying out participatoryobservational research in an ethnographic tradition 
(Czarniawska 2007; Hammersley and Atkinson 2007). The database was a first activity of a newly established collaboration on energy efficiency amongst shipowners. One of its stated purposes was to enable the transfer of knowledge from larger shipping companies who had already worked for several years on energy efficiency to other shipping companies, of which many were smaller and had only just begun to work systematically on energy efficiency. This was a heterogenous group: the smaller companies owned as few as three ships, while the larger companies owned a fleet of tens or even more than a hundred of ships. For a range of reasons which will be further explored in the article, the project was considered to have failed in some key aspects. The collaborative initiative itself, however, lived on (Borg 2018).

We believe the case of the database to be interesting for two main reasons. First, while energy efficiency collaborations for knowledge sharing have been the topic of previous research, these have often focused on a larger set of networks (Jochem and Gruber 2007; Koewener et al. 2011; Wohlfarth et al. 2016). Not enough attention has been paid to what people in such energy efficiency collaborations actually do in practice when they say that they "share knowledge", and in particular on what infrastructure (e.g., databases) they rely on and how. By looking in-depth into a particular aspect of a single inter-organizational collaboration, and by drawing from literature on the organizing and managing of collaboration in other fields (e.g., Huxham and Vangen 2005), we thus hope to contribute to energy efficiency research. Second, we hope that the case can encourage a more thorough discussion in literature on the local and practical aspects of the maritime low carbon transition, as a contrast to the more often discussed international negotiations and regulation (Psaraftis 2018; Shi 2016). In agreement with Schwanen et al. (2011), we see a need for more research that looks beyond technical and economical levers in this transition. Moreover, while we do not question the importance of international regulation, the actual low carbon transition will only take place through changes in industry practices, processes which can be supported by also local interventions by states and/or others.

The paper has the following structure; in section 2, first, we present previous research on energy efficiency collaboration, and second, we draw from literature on the organizing of inter-organizational collaboration to motivate research questions for the paper. In section 3 , the methods and the site of study are presented. Section 4 presents empirical findings, and section 5 discusses and concludes the study.

\section{Maritime climate change mitigation, energy efficiency networks, and inter-organizational collaborations}

Barriers to energy efficiency related to lack of information are frequently cited in the maritime literature (Jafarzadeh and Utne 2014; Johnson and Andersson 2016; Rehmatulla and Smith 2015). Jafarzadeh and Utne (2014) refer in their study to fourteen different dimensions of this barrier. Broadly it can refer to a lack of information on energy performance of ships in markets, as well as the lack of information about costs and savings of specific measures that improve energy efficiency. The maritime domain is receptive to such barriers due to the difficulties involved in measuring the energy performance of ships, and also due to the many organizations often involved, where only a single party carries the fuel bill. If energy efficiency is difficult to monitor in contractual agreements between these parties (Rehmatulla and Smith 2015), or even internally in an organization (Poulsen and Johnson 2016), energy efficiency becomes difficult to manage and improve. Research has shown, for example in the bulk market, that owners of more energy-efficient ships do not get higher charter rates for their ships to any large extent (Adland et al. 2017; Agnolucci et al. 2014). In other words, charterers seem unwilling to pay more when chartering more energy-efficient ships, even though this would yield them lower fuel bills.

Strategies have been put forward to address these barriers. Agnolucci et al. (2014) proposed a need for more information on the energy use of ships measures in markets and organizations;

Any instrument facilitating the diffusion of information or reducing the costs of holding ship owners accountable to their energy efficiency claims will help increase the maximum amount that time charterers are will to pay for the increased energy efficiency and stimulate the uptake of energy efficiency investments. (p. 183).

There has been a development in this area in terms of public policy as well as through private initiatives. The 
$\mathrm{EU}$, for example, claims its monitoring, reporting, and verification (MRV) scheme:

will provide useful insights into the performance of individual ships, their associated operational costs and potential resale value. This will benefit ship owners, who will be better equipped to take decisions on major investments and to obtain the corresponding finance (EC 2013).

Private governance schemes have taken an interest in spreading information on ship's performance in the form of various indices (Poulsen et al. 2018; Scott et al. 2017), such as the Clean Shipping Index (Wuisan et al. 2012). Paint manufacturers like Jotun have contributed to developing an ISO standard 19030 that specify principles for measuring degradation in ship performance due to hull fouling (Søyland and Oftedahl 2016).

Further, technology transfer is an important part of international diplomatic negotiations in the IMO. The EU has in this context funded a network of Maritime Technology Cooperation Centers (MTCCs) which is run by the IMO in Kenya, China, Trinidad and Tobago, Panama, and Fiji. Norway similarly in 2019 funded the GreenVoyage-2050 project. The basis is resolution MEPC.229, adopted at MEPC 65 in 2013. Here, states decided to

identify and create an inventory of energy efficiency technologies for ships; identify barriers to transfer of technology, in particular to developing States, including associated costs, and possible sources of funding and make recommendations... (IMO 2013, p. 2).

While networks, indices, and inventories of measures seem like plausible solutions to a perceived set of mechanisms hindering the adoption of more energy-efficient technologies and practices, little research has yet been carried out that examine how these solutions work in practice. Poulsen et al. (2018), for example, point to the need for further longitudinal studies of what effect index schemes actually have on various market segments. Viktorelius and Lundh (2019) showed how an initiative to introduce new technology onboard vessels for monitoring energy use in shipping company in the end depended on local practices onboard. Rather than leading to immediate and obvious energy efficiency improvements, tensions between work with energy efficiency and existing practices were highlighted. von Knorring (2019) showed in a longitudinal study how providing a shipping company with detailed information on cost-effective energy efficiency measures through conducting an energy audit did not lead to savings over time. There is a need for more work that examines how information and knowledge is actually used and possibly transferred across organizations in various settings in practice.

In this paper, we wish to discuss a particular way of promoting the spread of knowledge and information on ship energy performance as well as measures that improve the said performance: through gathering relevant companies in energy efficiency networks, so that they can share knowledge and information directly inbetween each other. Sharing knowledge and information on energy efficiency directly among organizations in networks has been part of public policy to improve energy efficiency for decades in some countries, although not related to the maritime sector. In Switzerland and Germany, energy efficiency networks have been created since 1992 and 2002 respectively (Jochem and Gruber 2007; Koewener et al. 2011; Wohlfarth et al. 2016). These were constructed according to a particular system with two phases. The first begins with a consultation phase, where a consultant conducts a type of energy audit for each company in the network, which ends with a list of recommended measures. The second is the actual networking phase, where energy managers in the companies meet a couple of times per year to discuss various issues related to energy efficiency in their organizations (Koewener et al. 2011). To enable participants to share knowledge more openly, previous studies have highlighted the importance of participants not having the same customers. While actors from the same sector have more in common to share, being competitors can also limit the information sharing (Jochem and Gruber 2007; Koewener et al. 2011; Paramonova and Thollander 2016).

Collaboration for increased energy efficiency can be a successful strategy to increase investments and implementation of measures among the participants (Jochem and Gruber 2007). At the same time, some researchers have problematized the role of such initiatives, as these could also support the status quo or focus on only parts of the process. Palm and Thollander (2010) revisited their previous research on energy efficiency in different sectors of Swedish industry. They saw that some sectors rely on a great deal on networks of colleagues from similar companies, and others on consultants. A problem may lie in the former as it may mean "existing 
behaviors, perceptions and norms concerning energy efficiency may prevail." (p. 3259). As for the latter, consultants may be good at providing detailed knowledge on energy efficiency measures but are later not part of following up on implementation.

We studied for this paper a specific database project in an energy efficiency network, which was aimed at enabling knowledge and information-sharing between the members. While knowledge-sharing between companies is often mentioned as a success factor in the energy efficiency network literature, little attention seems to have been paid to studying how this happens over time. What kind of tools, procedures, databases, IT systems, or other artifacts play a role and how? In the material gathered for the case presented in this paper, we became concerned with the practicalities of creating a database - were there any clues in literature that would explain the difficulties we observed? To explore this, we turned to literature that concerned itself with studying the organizing and practices of inter-organizational collaborations in general.

This stream of literature told us that even though collaborations encompassing a variety of actors, competencies, and experiences might be necessary in order to achieve system change towards a more energyefficient shipping sector; such collaborations may face a number of inherent challenges that are often underestimated. Despite all the good intentions, establishing, managing, and sustaining inter-organizational collaboration can be difficult in practice (e.g., Ebers and Grandori 1997; Huxham and Vangen 2005; Waddock 1988). We identified two major themes.

First, to get disparate actors to meet in emerging inter-organizational collaborations, to agree to work towards a common goal, or, on how to achieve it, are not easy tasks. It can be challenging to create a shared vision that all partners agree upon. Indeed, issues related to common purposes, goals, or aims are frequently occurring topics in the collaboration literature (Hudson et al. 1999; Huxham and Vangen 2005). On the one hand, it is often argued that creating clear goals which all actors agree upon is important in order to create learning and knowledge-sharing and to achieve collaborative progress (e.g., Anslinger and Jenk 2004; Buckley et al. 2002). On the other hand, there may exist risks of conflicts due to variations in aspects like organizational and individual agendas, purposes and motives for participation, or resources and expertise (Huxham and Vangen 2004). There is thus a dilemma with regard to defining common aims: even if clarification will facilitate direction for the collaboration, open discussions about conflicting agendas might also cause awareness of differences (Huxham and Vangen 2004). In this way, while the possibility of getting access to the competencies and resources of other organizations is a common reason for initiating collaboration, these differences might also cause challenges as involved partners might aim for different things in the collaboration (Dacin et al. 1997). Therefore, instead of creating clearly defined goals, the only practical option is often to state common aims in a vague enough manner for no actor to disagree on, and then get started with some action instead.

Second, inter-organizational collaborations settings are continually changing (Ebers and Grandori 1997). Negotiations on, for example, purpose and organizational structure are iterative processes (Huxham and Vangen 2000), as collaborations are affected by both external and internal changes. Shifts in government policies or market disturbances are examples of external factors that can be of relevance. Internal factors affecting a collaboration include changes in memberships, such as when new actors join and others leave. As relationships between individuals are of high importance in collaborative settings, changes in participation on an individual level can cause re-negotiations about agendas and goals (Huxham and Vangen 2004). Changes within individual member organizations, such as restructures, acquisitions, and mergers, might similarly have consequences for the collaboration (Ebers and Grandori 1997; Huxham and Vangen 2004).

As relationships between involved partners develop over time, so will also the collaboration (Hudson et al. 1999). One model suggested that collaborations' development processes have the dynamic structures of a feedback loop, where reassessment, learning, and adaption processes might change previously implemented collaboration forms (Ebers and Grandori 1997). Moreover, when previous goals are reached, a new agenda must be negotiated (Huxham and Vangen 2004; Waddock 1988). Knowledge creation or sharing from previous activities thus add to inter-organizational collaboration's dynamic character (Waddock 1989).

In summary, the collaboration literature highlights two aspects of energy efficiency collaborations that should be of importance when conducting a case study of a collaboration and subsequently analyzing 
field material. First, creating a common goal, vision, and purpose is not unproblematic in practice, and may both hinder and aid the collaboration progress. Second, collaborations are sensitive to a range of external and internal changes, which make it likely for the collaboration to change dynamically over time. Finally, we are interested in how these aspects may affect how the outcomes of the database project were perceived by the actors involved in the project. These findings lead us to the research questions guiding this article:

- How was the outcome of the database project perceived?

- How did different articulated goals, visions, and purposes guide the creation of the database?

- How did internal and external changes affect the creation of the database?

In this manner, the paper aims to explore the complexities of establishing knowledge sharing practices between organizations through the creating of a database.

\section{Method}

With the interest of studying the organizing and managing of energy efficiency collaboration, the first author was recruited to aid in the development of the studied collaboration. She overtly participated as a researcher, carrying out participatoryobservational research (Czarniawska 2007), while actively contributing to the work of the collaboration's management team and in collaborative activities and projects. The second author became involved in the collaboration when the database project was in its final phase. The creation of a database had already been executed, and discussions about the project's outcome had been going on for some months. Second author later became research advisor for the collaboration.

The study was executed with the typical ethnographic strategy (Hammersley and Atkinson 2007): based on findings on the field, the research interest narrowed to focus on practices of knowledge sharing in general, and, more specifically, a project of developing a database of energy efficiency measures. Such an approach has been pointed out as highly suitable for explorations of inter-organizational fields as it allows for exploration of social dynamics (Zilber 2014), and of the details of everyday life (Ybema 2009). The advantages of this strategy include longitudinal participation and direct access to people and events. Also, it enabled us to test views directly as the phenomena unfolded in practice (Flyvbjerg 2006).

Czarniawska (2014) argues that this kind of arrangement, where the fieldwork is done by researchers becoming employees, is the superior approach to fieldwork. However, despite its positive outlooks, it can also be a difficult setup for the researchers. Bruyn (1963) highlights the challenges of balancing the two needs of being personally involved and at the same time being detached to the field.

With regard to the issue of bias, the authors applied the strategies of method- and data triangulation (Hammersley and Atkinson 2007). By using a variety of methods for field material collection (see section 3.1 for more details) and comparing material from different types of sources, the validity of the study was increased. The findings were strengthened further by the authors performing comparisons on accounts from different actors at different times on the same phenomenon.

The case in focus of this paper is a database project, executed within an emerging inter-organizational collaboration. The aim of the initiative is increased energy efficiency in the shipping industry in a European country. The collaboration is managed and administrated under the motto "shared knowledge" through a national industry association consisting of around 60 member companies. In 2012, the discussions about establishing a collaboration around the issues of energy efficiency intensified within the association. It resulted in the initiation of the database project, which received public funding.

The database project became the first activity within the emerging collaboration. ${ }^{1}$ Responsible for the project execution was a naval architect consultant. The main part of the work with developing the database was executed in 2014.

\footnotetext{
${ }^{1}$ Other central activities in the collaboration has over time also included the development of an educational workshop concept focusing on ship crews' role in relation to the challenge of increased energy efficiency as well as a network for energy experts aiming for knowledge sharing between land organizations.
} 
Field material collection and analysis

The study presented in this paper is based on extensive fieldwork. As the collection of field material, analysis, and studies of literature proceeded, additional findings supported the initial analysis of the database project being interesting as a case for studying knowledge sharing practices in energy efficiency collaborations. Since parts of the project had already been carried out before the start of our ethnographic study, in addition to studying actions and discussions in presence, the authors also had to explore the project in retrospect.

A range of materials was collected, as common in the ethnographic research tradition (Hammersley and Atkinson 2007): such as observations of actions and accounts of the management team; observing and participating in collaborative activities; executing semistructured interviews with the management team, partners and others; having informal conversations with a range of people; and, participating in industry events. In addition, different documents were collected, such as meeting notes, organizational charts, guidelines, PowerPoint presentations, workshop assignments, emails, webpage updates, newsletters, and tweets. Over a 2.5-years period, the authors executed fieldwork on around $1000 \mathrm{~h}$. The collected data was documented in about 250 fieldnotes and interview transcripts, each ranging between $1 / 2$ and 25 pages. Between June and November 2015, the first author was part-time physically located at the premises of the collaboration's management team. This enabled her to participate in and observe the team's work of organizing and managing the collaboration on a daily basis. She also participated in other collaborative activities and projects as well as interviewed and interacted with collaboration participants and other relevant actors. After November 2015 until February 2018, the authors continued to collect data by observing and participating in collaboration activities as well as performing interviews with people from the management team and others, although not as frequent.

From this rich material, an analysis was executed through an interpretive method performed in several steps (Charmaz 2014). First, variations in expressed perceptions about the database project among different actors were identified as an interesting theme. The continuous data collection was adjusted to this focus. In the next step, the material was coded, using the computer software NVivo. The first level of coding focused on specific actors and material relating to each of their stated perceptions about the project. Next, the coded material was categorized and compared to literature in an iterative process according to three identified topics: (1) how the outcome of the project was perceived; (2) how different goals, visions, and purposes guided the creation of the database; and (3) how internal and external changes affected the creation of the database.

\section{Findings}

The discussions to establish a collaboration within the association resulted in the implementation of a database project as an initial activity. A consultant was made responsible for the project execution. When the first author entered the scene, the majority of the database development phase was already achieved. However, discussions had arisen over the outcome of the project as the involved parties thought the database was never finalized or considered fully functional.

Identified main characters of the database project include the following:

$\mathrm{Paul}^{2}$ was responsible from the industry association for the emerging collaboration and the database project. He was the CEO for the association's subsidiary company managing the initiative, and his role included advocating for collaboration with both the association's member companies, possible funders, and others. Within the industry association and its member companies, there were discussions for years about potential collaboration on matters related to energy efficiency.

Thomas was a senior consultant working on a small naval-architect consultant firm. He was employed by hour to execute the database project as well as creating an educational workshop concept which was developed in parallel.

John was a senior chairman for the collaboration. In the early discussions of establishing an energy efficiency collaboration, he was as a representative from one of the association's member companies, but he left the setting before the database project started. In the autumn of 2015 , he returned to the collaboration in the role of a chairman.

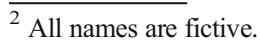


Perceived outcomes of the database project

The main outcome of the project was an open-source database, a so-called MySQL database. In the database, 465 ships were listed. Included was also basic information about these ships, such as ship sizes and engine powers. For a few ships, more extensive information was added, including information about implemented energy-saving measures onboard as well as the ships' specific energy distribution. The information included was mainly collected from public sources, such as shipping companies' websites. Other data, regarding for example the ships' main engines and deadweight tonnage, was based on Thomas' estimations.

For potential users of the database, the information was presented through a web reader. Depending on access, varying amount of information could be retrieved. In theory, this would allow the owners of the database to give a user access to the information about some ships but not all, for example, the ones belonging to the specific user's fleet. However, due to how the project developed and since much of the database never came into use, only a few people other than Thomas, Paul, and first author ended up having access.

In addition to the ship-specific information described above, a list of potential energy-saving measures was also developed and integrated into the database, see Fig. 1. In the end of the project, about 80 measures were in total included in the database. After the database project was terminated, additional ideas highlighted in other collaborative activities were also incorporated into the list.
Other outcomes of the database project included manuals about different energy-saving topics and measures that were created and integrated into the database. However, as illustrated in Fig. 1, much information about the measures' potential energy savings and costs were still lacking after the project ended.

An additional outcome of the database project was pedagogic and generic graphs over ships' energy distribution and speed power, see Fig. 2. The graph to the left illustrates the sizes of the energy losses in different parts of the ship; the farthest left indicates $100 \%$ of the energy going into the system, and the farthest right shows the power bringing the ship forward. Continuing, the right graph illustrates this power in relation to surrounding forces; the sizes of energy losses caused by varying resistances are indicated by the different colored fields, and the ships' speed can be read on the $x$-axis below. These graphs were interactive, and by adjusting potential ship data, such as the effects of propellers or shaft generators, they allowed the user to compare energy distributions between different real or potential ships.

In the end of the project, the involved parties did not consider the database to be finalized. Thomas estimated that the database was finalized "to $75 \%$ " but that there was still a need for more work for it to fully function as the tool he aimed for. Especially, more efforts were needed focusing on the programming of the opensource database, increasing the database's functionality and improving its IT security. For example; the link between the open-source database and the web reader did not allow the users to add or change information about the ships in an accessible manner.

\begin{tabular}{|c|c|c|c|c|c|c|c|}
\hline Add & Category & Effet & Measure & UnitSave & TotalSave & SavekW & Cost \\
\hline$\square$ & Accommodation & el & Galley Fan RPM Control & - & - & - & $\sim 18000 €$ \\
\hline$\square$ & & & Heating accommodation by $\mathrm{HT}$ cooling water & - & - & - & - \\
\hline$\square$ & & & Low Energy Light systems & - & - & - & $\sim 33000 €$ \\
\hline$\square$ & & & RPM control accommodation fan system & - & - & - & - \\
\hline$\square$ & & & Sun screen film on windows & - & - & - & $\sim 34000 €$ \\
\hline$\square$ & Cargo hold & el & Lighting Cargo hold & - & - & - & - \\
\hline$\square$ & & & RPM control cargo hold ventilation & - & - & - & - \\
\hline$\square$ & Engine & el & Pipe insulation for traced pipes & - & - & - & - \\
\hline$\square$ & Engine room & el & Air compressor optimisation & - & - & - & - \\
\hline$\square$ & & & Engine Room Ventilation Control & - & - & - & $\sim 19000 €$ \\
\hline$\square$ & & & Frequency controlled fedd water pumps for fuel system & - & - & - & - \\
\hline$\square$ & & & Lighting AE Room & - & - & - & - \\
\hline$\square$ & & & Lighting ME Room & - & - & - & - \\
\hline
\end{tabular}

Fig. 1 Screenshot of part of the list of energy-saving measures 


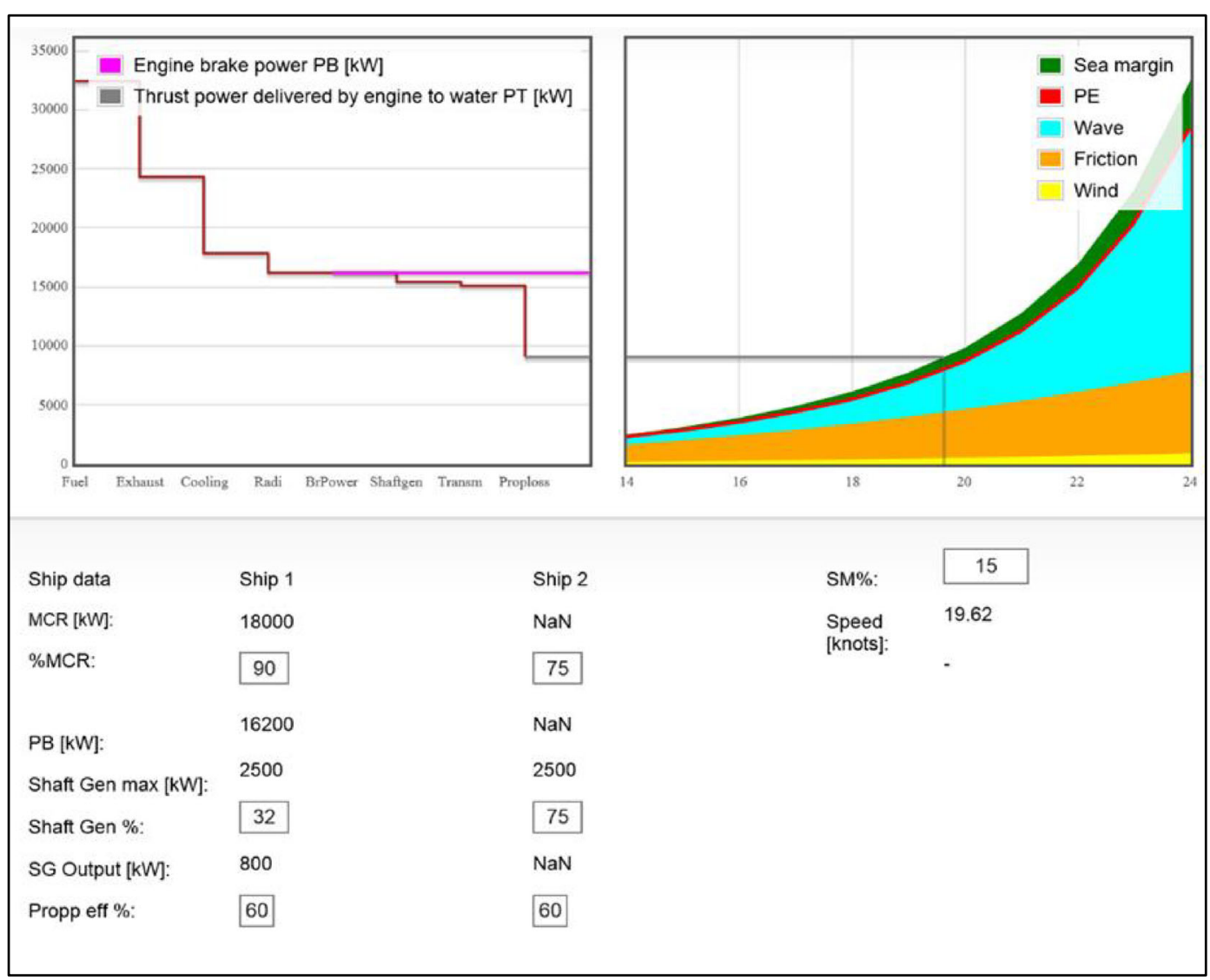

Fig. 2 Screenshot of pedagogic graphs over ships' generic energy distribution and speed power

From Paul's perspective, the database contained less information than he anticipated. For example, the database was mainly based on official or estimated information rather than based on operational data which was initially discussed. Also, there was a need to increase the information in the database regarding the specific ships as well as about the potential energy-saving measures.

Moreover, the database project and the emerging collaboration were initiated and managed by an industry association. Thus, Paul wanted the database to match their members' registered ships. However, Thomas did not use that list in the project as he stressed difficulties of getting access to it. Consequently, the ships he listed did not completely match the association's members' ships.

However, even if the database was considered nonfunctioning, after the termination of the database project, parts of the project outcome was still in use. The pedagogic graphs were utilized for educational purposes on the workshops for ship crews. Also, the list of potential energy-saving measures was continuingly growing as it was used for gathering ideas that were highlighted during the workshops. The extended version of this list was presented within the collaboration's network but described as an outcome from the workshops, rather than from the database project.

Goals, visions, and stated purposes

On an overall level, all involved actors stated a similar purpose for the database project: to develop a tool for knowledge sharing about energy efficiency measures between shipowners. However, as the authors analyzed the collected research material, it seems as similar descriptions had varying meanings for different actors. As a consequence, varying perceptions of the project idea and goals added to the discussions about the project outcome.

The perceptions about the purpose of the project and what a database should entail varied between the actors: Thomas highlighted the database as a "work tool", whereas Paul mainly focused on the database as a "collector" and "sharer "of information and knowledge. In 
addition, there was no project plan or description created describing and clarifying the project purpose.

Paul stressed the need for a database for collecting information about energy efficiency efforts in the shipping industry and knowledge about possible measures. He said he expected it to enable sharing of this information in different fashions and to different stakeholders; one was between different types of companies, as he described it:

\section{"Company A tries one measure - this is the result. \\ Then company B tries something else and evalu- ate that. Since the smaller companies cannot af- ford to take a risk, this set-up would help them as they can wait and see which measures the large companies try and the results from the evalua- tions." (Paul, March 2016, appr. quote, field note)}

Also, by mapping the sector's collective implemented energy efficiency measures, Paul wanted for the database to facilitate communication of the industry's efforts to policy-makers and the society.

Thomas expressed that he understood the task given to him with the database project as:

\section{"to make an inventory of [the industry associa- tion's members'] ships and their energy consump- tion as well as possible measures for improve- ments" (Thomas, Oct. 2015, appr. quote, field note)}

Thomas stated that he believed that in order to increase the shipping industry's energy efficiency, the companies would benefit from a catalyst that motivates and inspires them to increase their efforts. Thus, his vision for the overall collaboration was to establish a centrally placed consultant, supporting the companies through outreach activities. A key purpose for the database according to Thomas, was thus to create a tool enabling the work of the consultant. By collecting experiences from different companies about implemented energy-saving measures, a database of existing knowledge on the topic would be developed. Then, the consultant would be able to visit companies to discuss energy efficiency, presenting possible measures for them based on previous experiences from other companies. He viewed the development of the database as a continuous process; the more information the consultant would retrieve from its outreach activities, the more the database would evolve.
When John joined the collaboration, the database project was already executed. He expressed that if he would have been involved earlier, he would have advocated for another path instead of developing a database; improving the state-of-the-art by supporting the industry champions on energy efficiency - the companies that had come farthest with their energy efficiency efforts. However, as the project was already executed, he believed a possible future for the database would be to place it online and provide each company with the possibility to add information directly on a webpage. In addition, he highlighted what he considered was a lack of managerial and organizational focus in the database to complement included technical measures.

Paul and Thomas have both highlighted different possibilities for the database to be linked with the workshops for ship crews. Paul expressed that by making it mandatory for the participants to bring data about their specific ships, the workshops would offer a possibility to collect data to the database. Both highlighted the possibility of using the database as a pedagogic tool on the workshops.

Internal and external changes to the collaboration

Key events in the project are presented in Table 1 . During 2012, the discussions about establishing a col-

Table 1 Key events for the database project

\begin{tabular}{|c|c|}
\hline Year & Event \\
\hline 2012 & Discussions about collaboration intensified \\
\hline 2013 & Contact initiated between Paul and Thomas \\
\hline \multirow[t]{2}{*}{2014} & Received first project funding \\
\hline & Thomas executed project, project not finalized \\
\hline 2014-2016 & $\begin{array}{l}\text { Parts of project outcome started being utilized at } \\
\text { workshops for ship crews }\end{array}$ \\
\hline \multirow[t]{4}{*}{2015} & Discussions about project outcome \\
\hline & John and first author became involved \\
\hline & Thomas' role shifted \\
\hline & Negotiations about overall initiative focus \\
\hline \multirow[t]{3}{*}{2016} & Shift in overall initiative focus \\
\hline & Network for experts established \\
\hline & $\begin{array}{l}\text { Parts of project outcome enabled communication and } \\
\text { knowledge transfer between different } \\
\text { communities of practice: ship crews at educational } \\
\text { workshops and energy experts in the network }\end{array}$ \\
\hline 2016-2017 & $\begin{array}{l}\text { Need for documenting and collecting knowledge } \\
\text { from network }\end{array}$ \\
\hline
\end{tabular}


laboration regarding energy efficiency intensified within the industry association. The discussions were mainly held within the association's research and innovation committee. Both Paul and John later said that the collaboration idea gained wider approval at a members' meeting with up to 80 participants the same year.

During the autumn of 2013, Paul initiated contact with Thomas. When the collaboration received its first public project funding in 2014, it enabled the execution of developing a database. In parallel, in the emerging collaboration, Thomas was also responsible for developing an educational workshop focusing on the ship crews' role for increased energy efficiency.

Thomas stressed difficulties of receiving information from the shipping companies about their ships to integrate into the database. It appears as if there were varying perceptions about what type of data that was of interest. Paul, on the one hand, stressed the importance of "operational" data such as route choices and engine data. John agreed with Paul regarding the value of operational data, repeatedly stressing that "what gets measured gets done". On the other hand, Thomas argued that such information is not reliable, and thus focused on information about technical energy efficiency measures. He stated the importance of not letting the difficulties with measuring and analyzing operational data inhibit the continuing progress with energy efficiency. Instead, he stressed that it was better to be pragmatic and focus on other information sources for the database. However, also such information seemed to be difficult to collect, as some industry champions according to Thomas questioned their benefits of contributing with such data. Some information was still achieved and in addition, Thomas added data that he could collect from public sources or estimate based on his previous experience.

Thomas started receiving positive feedback from the other companies when presenting an early database prototype for the industry association's members. Apart from this presentation, both Thomas and Paul stressed that the communication between them was limited throughout the project. During 2015, the database project funding was finished, without having developed a functioning or finalized database.

During the autumn of 2015, John and first author became involved in the collaboration. Concurrently, Thomas's participation in the collaboration decreased. John had participated in the early discussions about a collaboration around the year 2012 but then left the setting for other engagements. After his return, he advocated for a different aim and structure for the overall collaboration. Instead of supporting less advanced companies (in terms of energy efficiency) by having them learn from the more advanced - facilitated by the database- he wanted the collaboration to focus on the companies who had already started working with energy efficiency and together improving the industry's stateof-the-art.

John partnered with the collaboration's then soonto-be research advisor (second author) and tried to convince also Paul and involved companies that a change was needed. At that time, the collaboration and its activities were mainly financed by public short-term project funding, and the management team put much time and resources into applying for continuing support. It seems as John's arguments about the necessity of a shift in order to receive such support contributed with him convincing enough actors to change the aim of the emerging collaboration. In parallel with the shift in focus, also the organizational structure of the emerging collaboration changed. The previous top-down approach aiming for a centrally placed consultant shifted into an approach where the management team had a more intermediary role.

The database, however, had been specifically developed to support the broader set of companies through a top-down approach: to enable collection of knowledge from the industry champions, and then sharing this with the rest of the industry. As mentioned above, in 2014, at a meeting for the association's members, Thomas presented his work so far. He has said that what he presented was a prototype of a tool rather than of the database it would be based on. Even though the prototype was positively received by the meeting participants, as the focus in the emerging collaboration shifted and the collaboration structure changed, the database - regardless of functioning or not- did no longer fit the overall vision.

During 2016, in accordance with the new focus, a network for energy experts in a limited number of champion companies was established. Within the network, a need for documentation on shared knowledge and experiences was expressed by both the management team as well as partner organizations participating in the collaboration. Thus, to facilitate this, a wish for a database was yet again highlighted by the participants. 


\section{Discussion and conclusions}

Making information on ship energy use and efficiency more widely available, and spreading knowledge of energy efficiency measures are two key strategies in decarbonizing maritime transport. These strategies can be connected to identified barriers in relation to lack of information about the energy performance of ships in markets, as well as the lack of information about costs and savings of specific measures that improve energy efficiency. More research has been called for on how such strategies lead to improvements in practice.

In this article, we examined the means by which an energy efficiency network first attempted to gather and spread information and knowledge, through creating a database. Literature from three fields was drawn upon in order to analyze and discuss the material gathered in the study: literature on energy efficiency in the maritime sector, on networks for energy efficiency, and on interorganizational collaboration. Taken together these fields have much to learn from each other. When applied to the case study, we found that there is more to sharing knowledge and information on energy efficiency than what is often assumed in the policy discourse (e.g., EC 2013). A database may perhaps be perceived as a relatively simple and neutral tool for storing and sharing information. However, in this case creating such a database was not simple.

First, even though the actors had the same overall goal with the database, differences emerged as the project was executed, in particular regarding perceptions about what the database should entail and what the purpose of the project was. This indicates how difficult it can be to achieve a shared vision before actually starting to collaborate; it appeared as they agreed on the project goal, but at the same time, they did not. Thus, we can add to the reasons described by Huxham and Vangen (2004) for setting out with a vague enough project goal and get started with actions instead: when the actors involved in the collaboration do not succeed with concretizing the project idea, a consequence can be that they start with the project before defining it. In hindsight, one could argue that defining the project idea earlier in the process would probably have been favorable. A crucial point is that the actual outcome of the project idea does not alone present a plausible explanation on why the project was not completed (see section 4): the vision on which it depended was also superseded by another overall strategy. These discussions illustrate the challenges of executing projects of which all actors are content with the outcome within a continuously changing setting. Even if the database would have met everybody's expectations they had when the project was initiated, due to the overall collaboration's shifts in focus and aim, the database would possibly not have met the expectations they had when the project was finalized.

Second, agreeing on shared goals is highlighted as important in energy efficiency collaboration literature (Jochem and Gruber 2007). The findings of this paper, however, illustrate the difficulties involved in such a task. Confirming previous research on interorganizational collaboration (Hudson et al. 1999; Huxham and Vangen 2005), the study shows that the initiative struggled with agreeing upon a shared goal for the database. Actors in collaborative settings each have their own agenda for their participation (Huxham and Vangen 2004). In the case of the database, the heterogeneous character of the collaboration could perhaps only be expected to make agreeing upon a shared vision on what the database should accomplish difficultly. For example, the needs and wishes of the larger and more experienced shipping companies were not the same as other less experienced. In this case, it was difficult for the lead consultant to motivate all actors to share information and participate in the collaboration for establishing the database. We thus find a typical contradiction with inter-organizational collaboration: The participants' differences in terms of competences and resources which motivates collaboration in the first place can also make the partners strive for different thingshence, challenge the collaboration's existence (Dacin et al. 1997).

Third, the literature emphasizes that interorganizational collaborative settings are dynamic (Huxham and Vangen 2005), so that collaboration between organizations develops continuously (Ebers and Grandori 1997). In our case, the collaboration setting, in which the database was developed, changed over time dependent on both internal and external shifts. This included changes to the prerequisites for funding and also memberships. New actors joined; others left or changed their level of engagement. All of this contributed to renegotiations regarding collaboration structure and focus within the studied initiative. After some time, the database no longer seemed to fit the overall vision, which changed from a top-down centralized approach to knowledge sharing to an approach that assumed that a smaller set of participants would share on more equal 
terms. Interestingly, as the collaboration continued to develop, discussions about the need of a database returned-but not necessarily in the same form as the previous one.

Concluding, as researchers and policy-makers tend to point towards knowledge sharing and collaboration as means towards sustainable development and a more energy-efficient society, it is important to be aware of the complexity of such tasks, and of the risk of underestimating inherent challenges. The paper has contributed to the discussion on how to improve energy efficiency in the maritime sector through gathering, providing, and spreading information and knowledge by focusing on following the development of a tool-a database - for doing so. The project itself was considered somewhat of a failure by its participants. As a consequence, rather than coming to conclusions on "best practices" for carrying out such work, for example, this case opens up for further questions. The case shows that behind seemingly simple strategies such as "providing information" and "sharing knowledge", all to improve energy efficiency, lies a more complicated reality. We hope that the paper can lead to further work on how these kinds of strategies are carried out in practice. For researchers who are interested and able to negotiate access, international examples of networks exist already such as the IMO Maritime Technology Cooperation Centers (MTCC) funded by the EU or the recent GreenVoyage-2050 project funded by Norway.

Funding Information Open access funding provided by Chalmers University of Technology.

Open Access This article is distributed under the terms of the Creative Commons Attribution 4.0 International License (http:// creativecommons.org/licenses/by/4.0/), which permits unrestricted use, distribution, and reproduction in any medium, provided you give appropriate credit to the original author(s) and the source, provide a link to the Creative Commons license, and indicate if changes were made.

\section{References}

Adland, R., Alger, H., Banyte, J., \& Jia, H. (2017). Does fuel efficiency pay? Empirical evidence from the drybulk timecharter market revisited. Transportation Research Part A: Policy and Practice, 95, 1-12.

Agnolucci, P., Smith, T., \& Rehmatulla, N. (2014). Energy efficiency and time charter rates: energy efficiency savings recovered by ship owners in the Panamax market. Transportation Research Part A: Policy and Practice, 66, 173-184.
Anslinger, P., \& Jenk, J. (2004). Creating successful alliances. Journal of Business Strategy, 25, 18-22.

Borg, J. (2018). Collaborating for energy efficient shipping: an ethnographic study. Licentiate thesis, Chalmers University of Technology, Sweden.

Bouman, E. A., Lindstad, E., Rialland, A. I., \& Strømman, A. H. (2017). State-of-the-art technologies, measures, and potential for reducing GHG emissions from shipping - a review. Transportation Research Part D: Transport and Environment, 52, 408-421.

Bruyn, S. (1963). The methodology of participant observation. Human Organization, 22, 224-235.

Buckley, P. J., Glaister, K. W., \& Husan, R. (2002). International joint ventures: partnering skills and cross-cultural issues. Long Range Planning, 35, 113-134.

Buhaug, O., Corbett, J. J., Eyring, V., Endresen, O., Faber, J., Hanayama, S., Lee, D. S., Lee, D., Lindstad, H., Markowska, A. Z., Mjelde, A., Nelissen, D., Nilsen, J., Palsson, C., Wanquing, W., Winebrake, J. J., \& Yoshida, K. (2009). Prevention of air pollution from ships - second IMO GHG study. London: International Maritime Organization.

Charmaz, K. (2014). Constructing grounded theory: a practical guide through qualitative analysis. London: Sage Publications.

Czarniawska, B. (2007). Shadowing: and other techniques for doing fieldwork in modern societies. Copenhagen: Copenhagen Business School Press.

Czarniawska, B. (2014). Social science research: from field to desk. London: SAGE Publications.

Dacin, M. T., Hitt, M. A., \& Levitas, E. (1997). Selecting partners for successful international alliances: examination of US and Korean firms. Journal of World Business, 32, 3-16.

Ebers, M., \& Grandori, A. (1997). The forms, costs and development dynamics of inter-organizational networking. In $\mathrm{M}$. Ebers (Ed.), The formation of inter-organizational networks. Oxford: Oxford University Press.

EC. (2013). Integrating maritime transport emissions in the EU's greenhouse gas reduction policies. Brussels: European Commission.

Eide, M. S., Endresen, Ø., Skjong, R., Longva, T., \& Alvik, S. (2009). Cost-effectiveness assessment of CO2 reducing measures in shipping. Maritime Policy \& Management, 36, 367384.

Eide, M. S., Longva, T., Hoffmann, P., Endresen, Ø., \& Dalsøren, S. B. (2011). Future cost scenarios for reduction of ship $\mathrm{CO}_{2}$ emissions. Maritime Policy \& Management, 38, 11-37.

Faber, J., Eyring, V., Selstad, E., Kågeson, P., Lee, D.S., Buhaug, O., Lindstad, H., Roche, P., Graichen, J., Cames, M., Schwarz, W., 2009. Technical support for European action to reducing greenhouse gas emissions from international maritime transport. CE Delft. Tender DG ENV.C3/ATA/ 2008/0016

Faber, J., Wang, H., Nelissen, D., Russell, B., \& Amand, D. (2011). Marginal abatement costs and cost effectiveness of energy-efficiency measures. London: International Maritime Organization.

Flyvbjerg, B. (2006). Five misunderstandings about case-study research. Qualitative Inquiry, 12, 219-245.

Hammersley, M., \& Atkinson, P. (2007). Ethnography: principles in practice. London: Routledge. 
Hudson, B., Hardy, B., Henwood, M., \& Wistow, G. (1999). In pursuit of inter-agency collaboration in the public sector: what is the contribution of theory and research? Public Management an International Journal of Research and Theory, 1, 235-260.

Huxham, C., \& Vangen, S. (2000). Leadership in the shaping and implementation of collaboration agendas: how things happen in a (not quite) joined-up world. Academy of Management Journal, 43, 1159-1175.

Huxham, C., \& Vangen, S. (2004). Realizing the advantage or succumbing to inertia? Organizational Dynamics, 33, 190201.

Huxham, C., \& Vangen, S. (2005). Managing to collaborate: the theory and practice of collaborative advantage. London: Routledge.

IMO. (2013). RESOLUTION MEPC.229(65): Promotion of technical co-operation and transfer of technology relating to the improvement of energy efficiency of ships. London: International Maritime Organization.

Jafarzadeh, S., \& Utne, I. B. (2014). A framework to bridge the energy efficiency gap in shipping. Energy, 69, 603-612.

Jochem, E., \& Gruber, E. (2007). Local learning-networks on energy efficiency in industry-successful initiative in Germany. Applied Energy, 84, 806-816.

Johnson, H., \& Andersson, K. (2016). Barriers to energy efficiency in shipping. WMU Journal of Maritime Affairs, 15, 79-96.

Koewener, D., Jochem, E., \& Mielicke, U. (2011). Energy efficiency networks for companies-concept, achievements and prospects. Proceedings of ECEEE, pp. 725-733.

Palm, J., \& Thollander, P. (2010). An interdisciplinary perspective on industrial energy efficiency. Applied Energy, 87, 32553261.

Paramonova, S., \& Thollander, P. (2016). Ex-post impact and process evaluation of the Swedish energy audit policy programme for small and medium-sized enterprises. Journal of Cleaner Production, 135, 932-949.

Poulsen, R. T., \& Johnson, H. (2016). The logic of business vs. the logic of energy management practice: understanding the choices and effects of energy consumption monitoring systems in shipping companies. Journal of Cleaner Production, 112, 3785-3797.

Poulsen, R. T., Hermann, R. R., \& Smink, C. K. (2018). Do ecorating schemes improve the environmental performance of ships? Marine Policy, 87, 94-103.

Psaraftis, H.N., 2018. Decarbonization of maritime transport: To be or not to be? Maritime Economics \& Logistics.
Rehmatulla, N., \& Smith, T. (2015). Barriers to energy efficiency in shipping: a triangulated approach to investigate the principal agent problem. Energy Policy, 84, 44-57.

Schwanen, T., Banister, D., \& Anable, J. (2011). Scientific research about climate change mitigation in transport: a critical review. Transportation Research Part A: Policy and Practice, 45, 993-1006.

Scott, J., Smith, T., Rehmatulla, N., \& Milligan, B. (2017). The promise and limits of private standards in reducing greenhouse gas emissions from shipping. Journal of Environmental Law, 29(2), 231-262.

Shi, Y. (2016). Reducing greenhouse gas emissions from international shipping: is it time to consider market-based measures? Marine Policy, 64, 123-134.

Søyland, S., \& Oftedahl, G. A. (2016). ISO 19030 - motivation (pp. 292-297). HullPIC, Turin: Scope and Development.

Viktorelius, M., \& Lundh, M. (2019). Energy efficiency at sea: an activity theoretical perspective on operational energy efficiency in maritime transport. Energy Research \& Social Science, 52, 1-9.

von Knorring, H. (2019). Energy audits in shipping companies. Transportation Research Part A: Policy and Practice, 125, 35-55.

Waddock, S. A. (1988). Building successful social partnerships. MIT Sloan Management Review, 29, 17.

Waddock, S. A. (1989). Understanding social partnerships: an evolutionary model of partnership organizations. Administration \& Society, 21, 78-100.

Wohlfarth, K., Eichhammer, W., Schlomann, B., Mielicke, U., 2016. Learning networks as an enabler for informed decisions to target energy-efficiency potentials in companies. Journal of Cleaner Production.

Wuisan, L., van Leeuwen, J., \& van Koppen, C. S. A. (2012). Greening international shipping through private governance: a case study of the clean shipping project. Marine Policy, 36, 165-173.

Ybema, S., 2009. Organizational ethnography: Studying the complexities of everyday life. SAGE Publications.

Zilber, T. (2014). Beyond a single organization: challenges and opportunities in doing field level ethnography. Journal of Organizational Ethnography, 3, 96-113.

Publisher's note Springer Nature remains neutral with regard to jurisdictional claims in published maps and institutional affiliations. 